\title{
Four year follow up of aortic valve replacement for isolated aortic stenosis: a link between reduction in pressure overload, regression of left ventricular hypertrophy, and diastolic function
}

\author{
I Ikonomidis, A Tsoukas, F Parthenakis, A Gournizakis, A Kassimatis, L Rallidis, \\ P Nihoyannopoulos
}

\begin{abstract}
Objective-To evaluate changes in left ventricular function and the impact of ventricular hypertrophy and pressure gradient early and late after aortic valve replacement in patients with isolated aortic stenosis.

Design-41 patients with isolated aortic stenosis and normal systolic function underwent cross sectional and Doppler echocardiography two months before and two weeks and four years after aortic valve replacement.

Results-Early after the operation, left ventricular mass index (mean (SD)) decreased from 187 (44) $\mathrm{g} / \mathrm{m}^{2}$ to $179(46) \mathrm{g} / \mathrm{m}^{2}$, because of a reduction in end diastolic diameter $(\mathrm{p}<0.05)$. Aortic pressure gradients were reduced, as expected. Isovolumic relaxation time was reduced from 93 (20) $\mathrm{ms}$ to 78 (12) ms, and deceleration time from 241 (102) ms to 205 (77) ms (p < 0.05). At four years, left ventricular mass index was further reduced to $135(30) \mathrm{g} / \mathrm{m}^{2}(\mathrm{p}<0.01)$ as a result of wall thickness reduction in the interventricular septum (from 14 (1.6) $\mathrm{mm}$ to 12 (1.4) $\mathrm{mm}, \mathrm{p}<0.01$ ) and the posterior wall (from $14(1.6) \mathrm{mm}$ to $12(1.3) \mathrm{mm}, \mathrm{p}<0.01$ ). Diastolic function, expressed by a reduction in isovolumic relaxation time from $93(20) \mathrm{ms}$ to 81 (15) $\mathrm{ms}(\mathrm{p}<0.01)$ and deceleration time from 241 (102) $\mathrm{ms}$ to $226(96) \mathrm{ms}(\mathrm{p}<0.05)$, remained improved. Prolonged isovolumic relaxation time was associated with significant septal and posterior wall hypertrophy (wall thickness $>13 \mathrm{~mm})(\mathrm{p}<0.05)$, whereas prolonged deceleration time was related to high residual gradient (peak gradient $>30 \mathrm{~mm} \mathrm{Hg}$ ) $(\mathrm{p}<0.01)$.

Conclusions-Left ventricular diastolic function improves early after surgery for aortic stenosis in parallel with the reduction in the aortic gradient. However, prolongation of Doppler indices of myocardial relaxation and ventricular filling is observed in patients with significant left ventricular hypertrophy and a residual pressure gradient early after surgery. At four years postoperatively, diastolic function remains improved.

(Heart 2001;86:309-316)
\end{abstract}

Keywords: diastolic function; hypertrophy regression; aortic valve replacement; aortic stenosis

Cardiology and
Cardiovascular
Surgery Department,
Imperial College
School of Medicine,
National Heart and
Lung Institute,
Hammersmith
Hospital, Du Cane
Road, London
W12 0NN, UK
I Ikonomidis
A Tsoukas
F Parthenakis
A Gournizakis
A Kassimatis
L Rallidis
P Nihoyannopoulos
Correspondence to:
Dr Nihoyannopoulos
petros@ic.ac.uk

Accepted 2 May 2001
A major determinant of left ventricular function in patients with aortic stenosis is pressure overload, leading to left ventricular hypertrophy. ${ }^{1-3}$ Several studies have linked ventricular hypertrophy to impaired left ventricular diastolic function in aortic stenosis. ${ }^{2-4}$ Animal studies have shown that pressure overload on its own also impairs myocardial relaxation. ${ }^{5}$ Aortic valve replacement for aortic stenosis reduces left ventricular pressure overload and wall stress, and subsequently reduces the amount of hypertrophy one year or more after surgery. ${ }^{6-8}$ Improvement in diastolic function after aortic valve replacement has been attributed mainly to the subsequent regression of left ventricular hypertrophy. ${ }^{6}{ }^{9}$ However, it is not clear whether the early reduction in pressure overload immediately after surgery, when hypertrophy is still present, also leads to improvement in diastolic function. Abnormal diastolic stiffness and myocardial structure have been observed one year after successful surgery for aortic stenosis ${ }^{10}$ and these may be related to both residual hypertrophy and aortic gradient. ${ }^{11}$ Impaired exercise capacity has also been related to abnormal diastolic a year after successful aortic valve replacement. ${ }^{12}{ }^{13}$

Regression of left ventricular hypertrophy following aortic valve replacement is dependent on multiple factors including valve size and residual pressure gradient. ${ }^{6-8}$ Often after successful aortic valve replacement only partial regression of left ventricular hypertrophy is observed. ${ }^{9}{ }^{1415}$ Consequently, the long term effect of residual pressure overload on regression of left ventricular hypertrophy, and its relation to diastolic function after aortic valve replacement for isolated aortic stenosis, has not been fully examined.

Cross sectional and Doppler echocardiography have been used extensively for assessing diastolic and systolic left ventricular function. ${ }^{16-19}$ In this study we used Doppler echocardiography to examine left ventricular diastolic function early after aortic valve replacement for isolated aortic stenosis and at four years of follow up. We hypothesised that 
Table 1 Characteristics of aortic prostheses

\begin{tabular}{llllll}
\hline AVR & $\begin{array}{l}\text { MECH } \\
(n=27)\end{array}$ & $\begin{array}{l}\text { BIO } \\
(n=14)\end{array}$ & AoV (m/s) & $\begin{array}{l}\text { PGR }(m m \\
\mathrm{Hg})\end{array}$ & $\begin{array}{l}\mathrm{MGR}(\mathrm{mm} \\
\mathrm{Hg})\end{array}$ \\
\hline Starr-Edwards & 19 & - & $2.9(0.5)$ & $38(13)$ & $22(8)$ \\
Bjork-Shiley & 6 & - & $3.0(1.0)$ & $41(30)$ & $22(15)$ \\
St Jude & 2 & - & $2.5(0.3)$ & $25(7)$ & $11(4)$ \\
Carpentier-Edwards & - & 14 & $2.0(0.3)$ & $17(6)$ & $9(4)$ \\
\hline
\end{tabular}

AoV, peak aortic velocity; AVR, aortic valve replacement; $\mathrm{BIO}$, bioprosthesis; $\mathrm{MECH}$, mechanical; MGR, mean pressure gradient; PGR, peak pressure gradient two weeks postoperatively.

the reduction in pressure overload early after aortic valve replacement would lead to improved left ventricular diastolic function, and that both residual left ventricular gradients and hypertrophy would adversely influence diastolic function early and late after surgery.

\section{Methods}

PATIENTS

This was a prospective study of 41 consecutive patients (28 men, 13 women) with isolated aortic stenosis and normal systolic ventricular function, undergoing aortic valve replacement between 1991 and 1992. Each patient underwent cross sectional and Doppler echocardiography two months before surgery (mean (SD): 2.0 (1.1) months, range 1-4 months), as well as two weeks (2.0 (1.0) weeks, range 1-3 weeks) and 48 months (48 (10) months, range 37-47 months) after aortic valve replacement. The first postoperative study was performed at two weeks to assess the early postoperative result of aortic valve replacement, as at that time patients have assumed their normal loading conditions just before discharge from hospital. Drug treatment affecting the loading conditions, such as diuretics or nitrates, was withdrawn 72 hours before each echocardiographic assessment. All patients had coronary angiography before surgery to assess the presence of coronary artery disease. Exclusion criteria were as follows:

- other associated valve disease;

- ejection fraction less than $50 \%$;

- patients with global hypokinesia (fractional shortening $\leqslant 29 \%$ ) or presence of regional wall motion abnormalities on echocardiography;

- atrial fibrillation;

- the need for the use of calcium channel blockers, $\beta$ blockers, or both either preoperatively or postoperatively.

All patients were in functional class II of the New York Heart Association (NYHA) classification before surgery. Twenty seven patients $(68 \%)$ had mechanical prostheses and $14(32 \%)$ had bioprostheses. The mean age of patients with bioprostheses was greater than that of patients with mechanical prostheses at the time of surgery, at 72 (11) v 59 (8) years $(p<0.05)$. Nine patients with mechanical prostheses $(34 \%)$ and six with bioprostheses $(41 \%)$ had additional incidental coronary artery disease (no flow limiting stenoses) detected during cardiac catheterisation before surgery (NS). None had a previous myocardial infarct and all had one or more bypass grafts at the time of surgery. There were no differences in sex or incidence of coronary artery bypass grafting (CABG) between the two groups.

The distribution of mechanical valves was as follows: Starr-Edwards 19, Bjork-Shiley 6, St Jude 2. All biological prostheses were porcine Carpentier-Edwards valves (table 1). The mean size of aortic prostheses was similar between patients with mechanical prostheses and bioprostheses, at 23 (1.7) v 22.9 (1.7) $\mathrm{mm}$ (NS). Thirty six patients (23 with mechanical prostheses and 13 with bioprostheses) had a follow up study four years (48 (10) months) after aortic valve replacement. The remaining four patients were lost to follow up. All patients were in NYHA class I, did not have angina, and had a negative exercise treadmill test for ischaemia four years after surgery.

ECHOCARDIOGRAPHY AND DOPPLER STUDIES All studies were performed using a Toshiba Sonolayer SSH 160A phased array ultrasound system (Toshiba Inc, Tokyo, Japan). A 3.75 MHz transducer was used for cross sectional imaging, a $2.5 \mathrm{MHz}$ duplex transducer for combined cross sectional imaging and Doppler, and a $2 \mathrm{MHz}$ stand alone pencil probe for continuous wave Doppler. The following variables were measured from cross sectional echocardiographic images of the left ventricle:

- end diastolic and end systolic diameter $(\mathrm{mm})$;

- fractional shortening (\%);

- left atrial size (mm);

- ventricular septal and posterior wall thickness (mm);

- left ventricular mass and left ventricular mass index, using the formula proposed by the Penn Convention. ${ }^{20}$

Flow velocity profiles were obtained from apical projections of pulsed and continuous wave Doppler, and measurements were made using the software supplied with the ultrasound equipment. Mitral diastolic flow was determined after the pulsed Doppler sample volume was positioned at the tips of the mitral valve leaflets, and 7-11 cardiac cycles were recorded. The Doppler cursor was then moved toward the left ventricular outflow position and the sample volume was placed approximately $1 \mathrm{~cm}$ proximal to the aortic valve so that it would come in contact with the anterior mitral valve leaflet. Isovolumic relaxation time (ms) was measured as the interval between the end of the aortic click artefact and the onset of the mitral inflow waveform.

The following indices were measured from the mitral valve diastolic waveform: peak early (E) and atrial (A) flow velocities (cm/s), E:A ratio, acceleration time (ms) and acceleration rate $\left(\mathrm{m} / \mathrm{s}^{2}\right)$, and deceleration time $(\mathrm{ms})$ and deceleration rate $\left(\mathrm{m} / \mathrm{s}^{2}\right)$ of the left ventricular diastolic filling, using standard methodology as previously described. ${ }^{16-19}$

Velocity-time integral $(\mathrm{cm})$, peak aortic velocity, peak instantaneous gradient, and mean transaortic gradient ( $\mathrm{mm} \mathrm{Hg}$ ) were measured by perimetry of the left ventricular outflow tract waveform and the peak aortic 
Table 2 Cross sectional indices in all patients' aortic valve prostheses during the three consecutive studies

\begin{tabular}{llll}
\hline Echo indices & $\begin{array}{l}\text { Pre- } \\
(n=41)\end{array}$ & $\begin{array}{l}\text { Post } \\
(n=41)\end{array}$ & $\begin{array}{l}\text { Follow up } \\
(n=36)\end{array}$ \\
\hline LV mass $(\mathrm{g})$ & $339(84)$ & $327(88)^{\star}$ & $245(57) \dagger$ \\
LV mass index $\left(\mathrm{g} / \mathrm{m}^{2}\right)$ & $187(44)$ & $179(46)^{\star}$ & $135(30) \dagger$ \\
IVS (mm) & $14.0(1.6)$ & $14.0(1.8)$ & $12.0(1.4) \dagger$ \\
PW (mm) & $14.0(1.6)$ & $14.0(1.5)$ & $12.0(1.3) \dagger$ \\
EDD (mm) & $49.0(6.0)$ & $46.0(5.0)^{\star}$ & $47.0(5.0)$ \\
ESD (mm) & $30.0(6.0)$ & $33.0(7.0)^{\star}$ & $30.0(5.0)$ \\
FS (\%) & $36(7)$ & $32(17)^{\star}$ & $37(18)$ \\
LA (mm) & $37(7)$ & $37(7)$ & $37(6)$ \\
\hline
\end{tabular}

Values are mean (SD).

${ }^{\star} \mathrm{p}<0.05$, early $v$ late postoperative studies.

tp $<0.05 v$ preoperative study.

EDD, end diastolic diameter of left ventricle; ESD, end systolic diameter of left ventricle; FS, fractional shortening; IVS, interventricular septum; LA, left atrial dimension; LV mass, left ventricular mass; Post, two weeks postoperative; Pre-, preoperative study; PW, posterior wall.

waveform, respectively, using the equipment's software. RR interval (ms) was measured from simultaneous ECG recordings.

\section{STATISTICAL ANALYSIS}

All data were normally distributed by the normality test (Statworks 1.2, Macintosh). Unpaired comparison between patients with mechanical prostheses and those with bioprostheses, or patients with and without bypass graft surgery, were performed using the standard $\chi^{2}$ test for categorical data and the unpaired $t$ test for continuous data. Paired comparisons between preoperative and postoperative studies were performed using the two tailed $t$ test. Analysis of variance for repeated measurements was carried out to assess differences in echocardiographic indices between preoperative, postoperative, and follow up studies using Scheffé's correction to localise the source of any differences. Linear relations were checked using simple linear regression analysis. When an independent variable was related to more than one dependent variable, a stepwise regression analysis model (Statview 4.0, Macintosh) was used to exclude an interrelation between the examined variables. RR interval and age and type of valve (mechanical or biological) were forced in the regression analysis model to take account of any possible relation with the examined variables.

In patients with bioprostheses, the data distribution was unknown owing to the small sample size (14 patients). For this reason, the Mann-Whitney U test for non-paired comparisons was used. The Wilcoxon signed rank test for paired comparisons and the Spearman rank correlation coefficient for linear relations were used. The level of significance was established at $\mathrm{p}<0.05$. Values are expressed as mean (SD).

Assessment of reproducibility

In 20 randomly selected patients, measurements were repeated in a blinded manner by a second observer (PN). Differences between the two sets of measurements were not significant.

\section{Results}

CROSS SECTIONAL ECHOCARDIOGRAPHY

Preoperative study

Left ventricular mass, left ventricular mass index, and left ventricular wall thickness were abnormal in all the patients. End diastolic
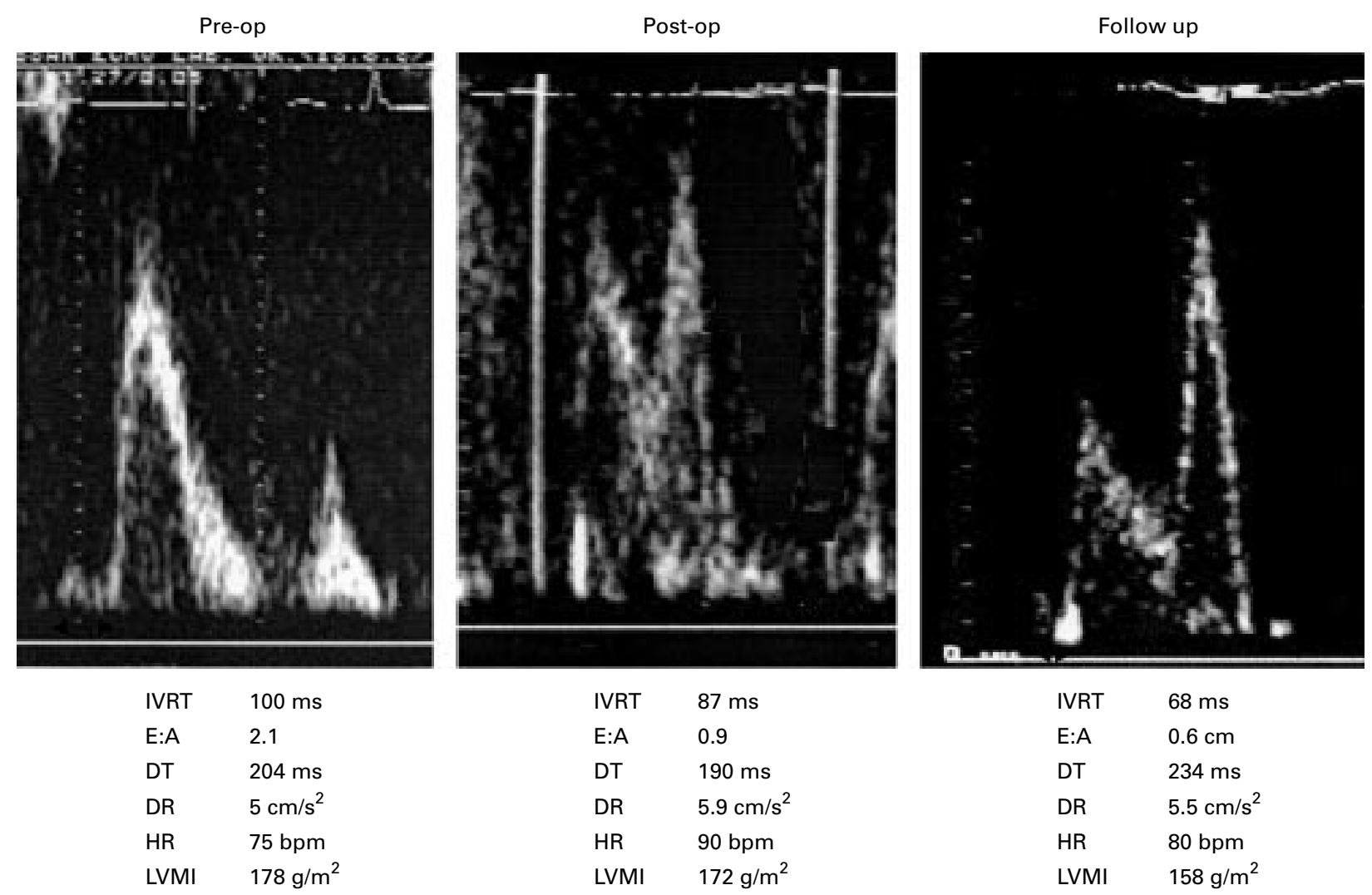

Figure 1 Changes of diastolic Doppler indices in a 68 year old patient with a bileaflet aortic prosthesis and significant residual aortic gradient (peak gradient, $38 \mathrm{~mm} \mathrm{Hg}$ ). Note the prolonged deceleration time after surgery which is maintained four years later despite the regression of hypertrophy. 
Table 3 Diastolic Doppler indices in all patients during the three consecutive studies

\begin{tabular}{llll}
\hline Doppler indices & Pre- $(n=41)$ & Post $(n=41)$ & $\begin{array}{l}\text { Follow up } \\
(n=36)\end{array}$ \\
\hline HR (beats/min) & $75(17)$ & $87(25)^{\star}$ & $74(16)$ \\
SBP $(\mathrm{mm} \mathrm{Hg})$ & $121(21)$ & $119(18)$ & $124(18)$ \\
DBP $(\mathrm{mm} \mathrm{Hg})$ & $82(13)$ & $78(11)$ & $83(14)$ \\
IVRT (ms) & $93(20)$ & $78(12)^{\star}$ & $81(15) \dagger$ \\
E:A & $1.05(0.5)$ & $1.0(0.5)$ & $0.91(0.3)$ \\
AT $(\mathrm{ms})$ & $76(20)$ & $62(16)^{\star}$ & $70(12)$ \\
AR $\left(\mathrm{m} / \mathrm{s}^{2}\right)$ & $8.4(3.8)$ & $11.9(5.0)^{\star}$ & $11.0(6.2) \dagger$ \\
DT $(\mathrm{ms})$ & $241(102)$ & $205(77)^{\star}$ & $226(96) \dagger$ \\
DR $\left(\mathrm{m} / \mathrm{s}^{2}\right)$ & $3.7(2.8)$ & $3.9(1.5)$ & $3.8(1.9)$ \\
\hline
\end{tabular}

Values are mean $(\mathrm{SD})$

${ }^{\star} \mathrm{p}<0.05$, early $v$ late postoperative studies.

tp $<0.05$ v preoperative study.

$\mathrm{AR}$, acceleration rate; AT, acceleration time; DBP, diastolic blood pressure; DR, deceleration rate; DT, deceleration time; $\mathrm{E}: \mathrm{A}, \mathrm{E}: \mathrm{A}$ ratio; HR, heart rate; IVRT, isovolumic relaxation time; Post, two weeks postoperatively; Pre-, preoperative study; SBP, systolic blood pressure.

Table 4 Systolic Doppler indices in all patients with aortic valve prostheses during the three consecutive studies

\begin{tabular}{llll}
\hline Echo indices & Pre- $(n=41)$ & Post $(n=41)$ & $\begin{array}{l}\text { Follow up } \\
(n=36)\end{array}$ \\
\hline HR (beats/min) & $75(17)$ & $87(25)^{\star}$ & $74(16)$ \\
AoV $(\mathrm{m} / \mathrm{s})$ & $4.8(0.7)$ & $2.6(0.7)^{\star}$ & $2.5(0.4) \dagger$ \\
MGR (mm Hg) & $59(19)$ & $17(10)^{\star}$ & $14(5) \dagger$ \\
PGR (mm Hg) & $94(29)$ & $31(17)^{\star}$ & $25(8) \dagger$ \\
\hline
\end{tabular}

Values are mean (SD).

${ }^{\star} \mathrm{p}<0.05$, early $v$ late postoperative studies.

tp $<0.05 v$ preoperative study.

AoV, peak aortic velocity; HR, heart rate; MGR, mean pressure gradient; PGR, peak pressure gradient; Post, two weeks postoperatively; Pre-, preoperative study.

diameter, end systolic diameter, and fractional shortening were within normal limits ${ }^{21}$ in all patients before surgery, and early and late after the operation (table 2).

Early postoperative study

Left ventricular mass was reduced $(\mathrm{p}<0.05)$ despite wall thickness remaining unchanged. Fractional shortening also decreased but remained within normal limits $(\mathrm{p}<0.05)$. These changes mainly reflected the reduction in left ventricular end diastolic dimension $(p<0.05)$.

Follow up study

Left ventricular mass decreased by $28 \%$ and $27 \%$ compared with the preoperative and postoperative studies, respectively, mainly because of a reduction in septal and posterior wall thickness $(p<0.01)$.

Mechanical prostheses versus bioprostheses All echocardiographic indices were similar between patients with biological and mechanical prostheses before and after surgery.
DOPPLER ECHOCARDIOGRAPHY

An example of the Doppler echographic findings is shown in fig 1 .

\section{Preoperative study}

Isovolumic relaxation time, acceleration time, and deceleration time were all prolonged (table 3). Peak aortic velocities and pressure gradients were similarly high in all patients (table 4 ).

Early postoperative study

Indices of volume loading conditions were similar to preoperative studies. Isovolumic relaxation time, acceleration time, and deceleration time decreased by $16 \%(p<0.01), 18 \%(p<0.01)$, and $16 \%(\mathrm{p}<0.05)$, respectively. Acceleration and deceleration rates increased by $38 \%$ $(\mathrm{p}<0.01)$ and $5 \%$, while the E:A ratio remained largely unchanged (table 3 ). Peak aortic velocities and pressure gradients decreased as expected $(\mathrm{p}<0.01)$ (table 4$)$.

Follow up study

The early postoperative reduction in isovolumic relaxation time and deceleration time was maintained late postoperatively (table 3). Peak aortic velocities and pressure gradients remained low at the four year follow up, and similar to the early postoperative values (table 4).

MECHANICAL PROSTHESES VERSUS BIOPROSTHESES Preoperative study

Isovolumic relaxation time was longer in patients who received bioprostheses than in those who received mechanical prostheses, at 111 (15) ms $v 85$ (13) ms ( $\mathrm{p}<0.05)$. This difference possibly reflects the older age of patients with bioprostheses, who also had a lower E:A ratio (0.84 (0.4) v 1.02 (0.4), $\mathrm{p}<0.05)$. Preoperatively, pressure gradients were similar between patients who received biological prostheses and those who received mechanical prostheses (NS).

Early postoperative study

The values of all diastolic indices were similar between patients with mechanical valves and bioprostheses. Peak aortic velocity and pressure gradients were greatly reduced in all patients after surgery $(\mathrm{p}<0.001)$ (table 5$)$. However, pressure gradients were higher in patients with mechanical prostheses than in those with bioprostheses (peak gradient 34 (17) $\mathrm{mm} \mathrm{Hg} v 17$ (6) $\mathrm{mm} \mathrm{Hg}$, mean gradient 21 (10) $\mathrm{mm} \mathrm{Hg} v 9$ (4) $\mathrm{mm} \mathrm{Hg}$; p < 0.05). Conversely, peak velocity in the outflow tract and velocity-time integral were similar between patients with mechanical prostheses and bioprostheses (NS).

Table 5 Effects of left ventricular hypertrophy and residual gradient on indices of diastolic function two weeks postoperatively

\begin{tabular}{|c|c|c|c|c|c|c|}
\hline \multirow[b]{2}{*}{ Diastolic index } & \multicolumn{3}{|c|}{ Wall thickness (mm) } & \multicolumn{3}{|c|}{ Peak pressure gradient $(\mathrm{mm} \mathrm{Hg})$} \\
\hline & $\leqslant 13(n=14)$ & $>13(n=27)$ & $p$ Value & $\leqslant 30(n=19)$ & $>30(n=22)$ & $p$ Value \\
\hline IVRT (ms) & $71(11)$ & $82(11)$ & $<0.01$ & $79(9)$ & $78(15)$ & NS \\
\hline DT (ms) & $184(41)$ & $217(89)$ & NS & $180(64)$ & $230(83)$ & $<0.05$ \\
\hline $\mathrm{E}: \mathrm{A}$ & $1.2(0.5)$ & $0.86(0.29)$ & $<0.01$ & $0.9(0.4)$ & $1.0(0.5)$ & NS \\
\hline
\end{tabular}

Values are mean (SD)

DT, deceleration time; E:A, E:A ratio; IVRT, isovolumic relaxation time; Wall thickness, thickness of both ventricular septum and posterior wall. 

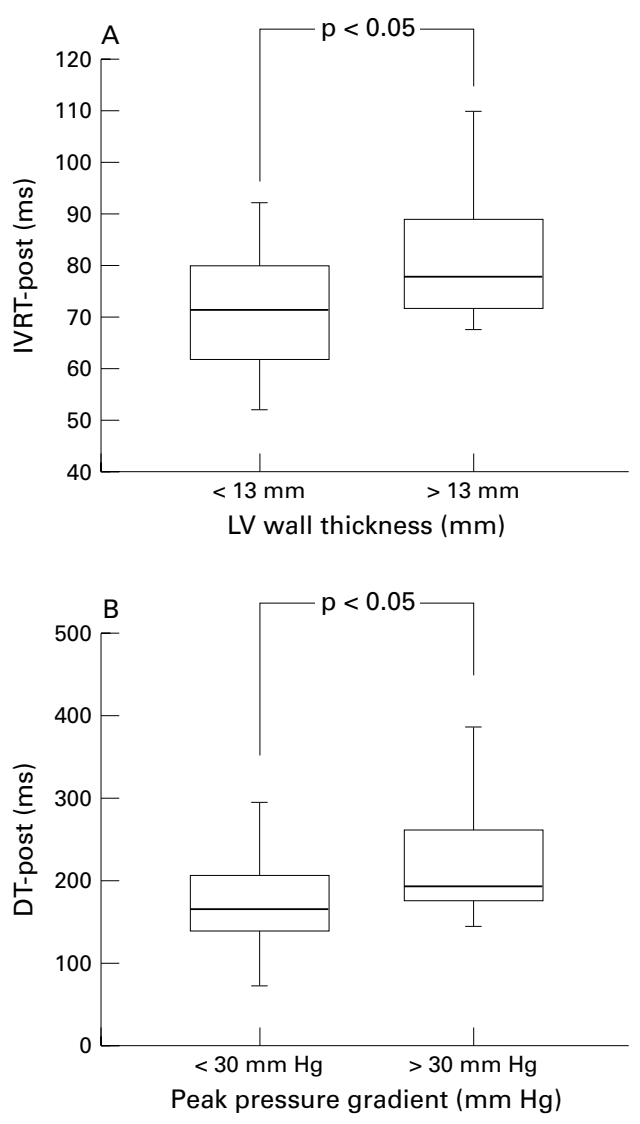

Figure 2 (A) Isovolumic relaxation time in patients in whom both ventricular septal and posterior wall thickness values were $>13 \mathrm{~mm}(n=26)$ compared with those with wall thickness values $<13 \mathrm{~mm}(n=15)$ two weeks after aortic valve replacement. IVRT-post, isovolumic relaxation time (ms). (B) Deceleration time in patients with a peak pressure gradient of $>30 \mathrm{~mm} \mathrm{Hg}(n=22)$ compared with those with a peak pressure gradient $<30 \mathrm{~mm} \mathrm{Hg}(n=19)$ two weeks after aortic valve replacement. DT-post,

deceleration time (ms) two weeks postoperatively. Values are represented as box plots. The middle line represents the

median of the values, the upper and lower lines represent the 25 th and 75 th centiles, respectively, and the T lines represent the minimum and maximum values.

Follow up study

The values of all diastolic indices were again similar between patients with mechanical prostheses and bioprostheses (NS). Interestingly, peak aortic velocity and pressure gradients became similar between patients with biological and mechanical prostheses four years after surgery. This change reflected a $20 \%$ increase in pressure gradients in patients with bioprostheses during follow up compared with the postoperative study (22 (6) $\mathrm{mm} \mathrm{Hg} v 17$ (6) mm Hg, p < 0.05).

CORONARY ARTERY BYPASS GRAFTING

All indices were similar during the three consecutive studies among the 14 patients with and the 27 without simultaneous CABG and aortic valve replacement.

RELATIONS BETWEEN DIASTOLIC INDICES, LEFT VENTRICULAR HYPERTROPHY, AND PRESSURE OVERLOAD

Preoperative study

Prolonged deceleration time was related to high left ventricular wall thickness (posterior wall, $r=0.47$; ventricular septum, $r=0.42$; $\mathrm{p}<0.01)$. Patients in whom both ventricular septal and posterior wall thickness values were $>13 \mathrm{~mm}(26 / 41)$ had longer deceleration times than those with wall thickness values $<13 \mathrm{~mm}$ (269 (105) ms v 190 (72) ms; $\mathrm{p}<0.01)$. The two subgroups had similar mean gradients.

\section{Postoperative studies}

The two subgroups had similar septal and posterior wall thickness measurements. In the early postoperative period, the longer the isovolumic relaxation time the greater the wall thickness (posterior wall, $r=0.35$; ventricular septum, $r=0.34 ; \mathrm{p}<0.05)$. Patients with wall thickness values of $>13 \mathrm{~mm}(26 / 41)$ had longer isovolumic relaxation time (fig $2 \mathrm{~A}$ ) and a lower E:A ratio than those with wall thickness values $<13 \mathrm{~mm}(\mathrm{p}<0.01$, table 5$)$. The two subgroups had similar peak and mean pressure gradients. During follow up, when hypertrophy had regressed, no relation between Doppler diastolic indices and aortic pressure gradients or wall thickness was noted. Furthermore, a prolonged deceleration time was related to high residual pressure gradient $(r=0.42$ and $r=0.35$, respectively; $\mathrm{p}<0.01)$ and to small valve size $(r=0.45 ; \mathrm{p}<0.05)$; patients with a peak gradient of $>30 \mathrm{~mm} \mathrm{Hg}(22 / 41)$ had a longer deceleration time than those with a gradient of $<30 \mathrm{~mm} \mathrm{Hg}$ (table 5) (fig 2B).

AGE AND DOPPLER INDICES

Prolonged isovolumic relaxation time and low $\mathrm{E}: \mathrm{A}$ ratios were associated with older age preoperatively $(r=0.42$ and $r=0.46$; $\mathrm{p}<0.01)$. Of all diastolic indices, only a low $\mathrm{E}: \mathrm{A}$ ratio was related to older age in the early postoperative period $(r=0.46 ; \mathrm{p}<0.01)$. During follow up, longer isovolumic relaxation time and lower E:A ratios were observed in older patients $(r=0.48, r=0.50 ; \mathrm{p}<0.01)$.

\section{Discussion}

Several investigators have studied left ventricular function after aortic valve surgery, either invasively $y^{1011} 13$ or by radionuclide angiocardiography. ${ }^{9}$ Although these methods have expanded our knowledge of left ventricular function, they cannot be performed routinely because of their invasive nature and because of radiation hazards. Early studies used $M$ mode echocardiography to assess left ventricular function, but the information gained was not representative of the entire left ventricle. ${ }^{22-24}$ Doppler echocardiography is a unique technique for evaluating left ventricular function and has the ability to attain higher temporal resolution than nuclear techniques, with good intraobserver and interobserver variability. ${ }^{25}$

This is the first prospective study to our knowledge to show that the reduction in pressure overload two weeks after aortic valve replacement for pure aortic stenosis results in rapid improvement in myocardial relaxation and early diastolic filling. Four years after surgery, when hypertrophy had regressed, this improvement was maintained despite the patients' advancing age and the presence of a residual gradient. 
DIASTOLIC FUNCTION AFTER AORTIC VALVE REPLACEMENT

Early postoperative period

In aortic stenosis, pressure overload causes left ventricular hypertrophy, ${ }^{1-3}$ subendocardial ischaemia, ${ }^{36-28}$ fibrosis, ${ }^{10}$ and subsequently impaired myocardial relaxation, ${ }^{1-4} 2627$ even in the presence of preserved systolic function. ${ }^{2}$ Aortic valve replacement reduces pressure overload to a variable extent, depending on the type of artificial valve, ${ }^{6}{ }^{14}{ }^{29}$ and leads to regression of hypertrophy. ${ }^{9} 30$ Improvement of diastolic function after aortic valve replacement has been mainly attributed to the subsequent regression of left ventricular hypertrophy. ${ }^{9} \quad$ In this study we have shown that myocardial relaxation and early diastolic filling rapidly improves two weeks after aortic valve replacement. Left ventricular mass index was reduced early postoperatively but wall thickness remained unchanged. This small but significant change in left ventricular mass index can be explained by the predominant reduction in left ventricular end diastolic diameter, as opposed to wall thickness, as the former is algebraically the major determinant in the calculation of left ventricular mass. ${ }^{2031}$ Thus the improvement in diastolic function two weeks after surgery is more likely to be attributed to the sudden reduction in pressure overload, perhaps followed by improved coronary flow reserve, wall thickness remained largely unchanged while loading conditions remained the same. This is supported by studies in open chest dogs, which showed that tau increased significantly when peak systolic pressure was suddenly increased by cross clamping the ascending aorta during diastole. ${ }^{5}$ Additionally, Duel and colleagues found abnormal myocardial relaxation in a small cohort of patients with high peak systolic pressure and normal left ventricular mass one year after aortic valve replacement. $^{11}$

\section{Late postoperative period}

Deterioration of diastolic function with concomitant prolongation of Doppler diastolic indices is common with advancing age. ${ }^{32} 33$ However, four years after surgery, the early postoperative improvement in diastolic function was maintained despite the patients' advancing age and the presence of a small residual gradient. Left ventricular mass index was reduced by $30 \%$ late after operation, compared with the early postoperative studies, mainly because of a significant reduction in wall thickness. Thus preservation of the good postoperative result four years after surgery is attributable to the effect of regression of hypertrophy on diastolic function. These observations are in agreement with those of Lund and colleagues, who used radionuclide angiocardiography and also found an improvement in left ventricular diastolic filling associated with regression of hypertrophy one year after aortic valve replacement. ${ }^{9}$

Regression of left ventricular hypertrophy following aortic valve replacement is dependent on many factors, including valve size and residual pressure gradient. ${ }^{6-8}$ In our study, wall thickness was normalised four years after surgery, despite the presence of a significant residual gradient in mechanical prostheses and the $20 \%$ increase in pressure gradient in bioprostheses. Thus a residual pressure gradient caused by the artificial valve did not appear to inhibit regression of ventricular hypertrophy four years after aortic valve replacement.

EFFECTS OF HYPERTROPHY AND RESIDUAL

GRADIENT ON DIASTOLIC FUNCTION

The extent of hypertrophy is unlikely to be the sole determinant of impaired diastolic function, as experimental studies have shown that pressure overload on its own impairs myocardial relaxation. ${ }^{5}$ In our study, wall thickness played a dominant role in left ventricular diastolic filling as increased wall thickness was associated with prolongation of deceleration time. Patients with severe hypertrophy (wall thickness $>13 \mathrm{~mm}$ ) had a longer deceleration time and a lower E:A ratio than patients with similar degree of aortic stenosis but moderate ventricular hypertrophy. Prolonged deceleration time was associated with a residual pressure gradient early after surgery, suggesting a significant effect of residual pressure overload on left ventricular diastolic filling. Patients with a peak pressure gradient of more than $30 \mathrm{~mm} \mathrm{Hg}$ had a longer deceleration time than those with a gradient of less than $30 \mathrm{~mm} \mathrm{Hg}$, while the degree of left ventricular hypertrophy was similar. Furthermore, a prolonged isovolumic relaxation time was observed in patients with increased wall thickness, linking the effect of hypertrophy to myocardial relaxation. Therefore, our data suggest that both hypertrophy and residual pressure overload determine left ventricular diastolic function early after aortic valve replacement.

Four years after surgery, when hypertrophy had regressed, no relation between Doppler diastolic indices and aortic pressure gradients or wall thickness was noted. This suggests that the beneficial effect of regression of left ventricular hypertrophy had possibly outweighed the adverse effects of advancing age and residual pressure gradient on diastolic function late after surgery.

MECHANICAL PROSTHESES VERSUS BIOPROSTHESES Diastolic dysfunction was worse preoperatively in patients who received bioprostheses than in those who received mechanical valves. This difference is probably attributable to the older age at which patients received bioprostheses, as the two groups were otherwise similar. ${ }^{32} 33$ Interestingly, however, diastolic Doppler indices were also similar between the two groups in the early postoperative period despite the age difference. This was because of the greater reduction in diastolic functional indices in patients with bioprostheses.

CABG AND DIASTOLIC FUNCTION

The effects of ischaemia on diastolic function have been well described. ${ }^{26} 27$ In our study, Doppler indices of diastolic function were 
similar between patients with and without concomitant coronary artery bypass graft surgery. The lack of such difference preoperativelywhen ischaemia from coronary artery disease was at least theoretically present-should perhaps be attributed to the greater contribution of pressure overload and hypertrophy in determining left ventricular function or indeed to the absence of significant ischaemia.

\section{STUDY LIMITATIONS}

Optimal assessment of left ventricular function after surgery for isolated aortic stenosis is difficult because of the multiple changes occurring after aortic valve replacement, including changes in atrial pressures, left ventricular systolic pressure, loading conditions, and systolic function. These may all affect Doppler indices. Thus the causal link between changes in left ventricular function and echocardiographic/Doppler values may be difficult to confirm, irrespective of the diagnostic technique.

In an effort to reduce the number of variables, we enrolled patients with isolated aortic stenosis and normal systolic function, who were not taking any drug treatment that could have affected loading conditions preoperatively or postoperatively. We therefore excluded patients with impaired systolic function before surgery, so that the measured Doppler diastolic indices and pressure gradients were not affected by increased atrial pressures and depressed myocardial contractility. We do not believe that the few patients with coronary artery disease affected the balance of our homogeneous population, as there was no evidence of concomitant myocardial ischaemia. The bypass grafting was performed more as a preventive procedure to avoid the future need for repeat surgery for coronary artery disease.

Changes in loading conditions may lead to reciprocal changes in Doppler diastolic indices. $^{34}{ }^{35}$ We were unable, however, to monitor changes in loading conditions and left atrial filling pressures postoperatively. A reduction in left ventricular overload by drug treatment alone has not been shown to cause significant changes in myocardial relaxation or filling in patients with aortic stenosis. ${ }^{36}$

\section{CONCLUSIONS}

Left ventricular diastolic function improves early after surgery for isolated aortic stenosis, in parallel with the reduction in aortic gradient. At four years postoperatively, diastolic function remains unchanged in comparison with the early postoperative period despite advancing age and the presence of a residual gradient. This may reflect significant regression of hypertrophy.

1 Hanrath P, Mathey DG, Siegert R, et al. Left ventricular relaxation and filling pattern in different forms of left ventricular hypertrophy: an echocardiographic study. $A m \mathcal{F}$ Cardiol 1980;45:15-23.

2 Eichorn P, Grimm J, Koch R, et al. Left ventricular relaxation in patients with left ventricular hypertrophy sec-
ondary to aortic valve disease. Circulation 1982;65:1395ondary.
3 Shapiro LM, Gibson DG. Patterns of diastolic dysfunction in left ventricular hypertrophy. Br Heart $\mathcal{f}$ 1988;59:438 45.

4 Wickmann-Cofelt J, Parmley WW, Mason DT. The cardiac hypertrophy process. Analysis of factors determining pathological vs physiological development. Circ Res 1979; 45:697-74.

5 Gaash WH, Blaustein A, Andrias CW, et al. Myocardial relaxation II. Hemodynamic determinants of the rate of left ventricular isovolumetric pressure decline. Am $\mathcal{f}$ Physiol 1980;295: H1-6.

6 Bech Hanssen O, Caidahl K, Wall B, et al. Influence of aortic valve replacement, prosthesis, type and size on functional outcome and ventricular mass in patients with aortic stenosis. F Thorac Cardiovasc Surg 1999;118: $57-65$.

7 Morris JJ, Schaff HV, Mullany CJ, et al. Determinants of survival and recovery of left ventricular function after aortic valve replacement. Ann Thorac Surg 1993;56:22-30.

8 Sim EK, Orszulak TA, Schaff HV, et al. Influence of prosthesis size on change in left ventricular mass following aortic valve replacement. Eur F Cardiothorac Surg 1994;8: 293-7.

9 Lund O, Jensen FT. Functional status and left ventricular performance late after valve replacement for aortic stenosis. Relation to preoperative data. Eur Heart $\mathcal{F} 1988 ; 9$ : $1234-43$

10 Hess OM, Ritter M, Schneider MSJ, et al. Diastolic stiffness and myocardial structure in aortic valve disease before and after aortic valve replacement. Circulation 1984;69:855-65.

11 Duel W, Hess OM, Turina M, et al. Left ventricular relaxation at rest and during handgrip in aortic valve disease before and after aortic valve replacement. Eur Heart $f$ 1983;4:592-8.

12 Oldershaw PJ, Dawkins KD, Ward DE, et al. Diastolic mechanisms of impaired exercise tolerance in aortic valve disease. Br Heart f 1983;49:568-73.

13 Monrad ES, Hess OM, Corin WJ, et al. Abnormal exercise hemodynamics late after aortic valve replacement [abstract]. Circulation 1986;74(suppl II):398.

14 Nihoyannopoulos P, Kambouroglou D, Athanassopoulos G, et al. Doppler haemodynamic profiles of clinically and echocardiographically normal mitral and aortic valve prostheses. Eur Heart f 1992;13:348-55.

15 Dubois C, Soyer D, Demoulin JC, et al. Echocardiography in aortic valve replacement [abstract]. Eur Heart $\mathcal{f}$ 1985;6(suppl 1):33.

16 Nishimura RA, Housmans PR, Hattle LK, et al. Assessment of diastolic function of the heart: Background and current applications of Doppler echocardiography. Part I. Physiologic and pathophysiologic features. Mayo Clin Proc 1989; 64:71-81.

17 Nishimura RA, Abel MD, Hattle LK, et al. Assessment of diastolic function of the heart: background and current applications of Doppler echocardiography. Part II. Clinical studies. Mayo Clin Proc 1989;64:181-204.

18 Danford DA, Huhta JC, Murphy DJ. Doppler echocardiographic approaches to ventricular diastolic function. Echocardiography 1986;3:33-9.

19 Labovitz AJ, Pearson AC. Evaluation of left ventricular diastolic function: clinical relevance and recent Doppler insights. Am Heart f 1987;114:836-51.

20 Devereux R, Reichek N. Echocardiographic assessment of left ventricular mass in man. Circulation 1977;55:613-18.

21 Weyman AE. Normal cross sectional echocardiographic measurements. In: Names of editors. Principles and practice of echocardiogaphy, 2nd ed. New York: Lea and Febiger,
1994:1289-98.

22 Bahler RC, Vrobel TR, Martin P, et al. The relation of heart rate and shortening fraction to echocardiographic indexes of left ventricular relaxation in normal subjects. $\mathcal{F} \mathrm{Am}$ Coll Cardiol 1983;2:926-33.

23 Gibson I, Brown D. Measurement of instantaneous left dimension and filling rate in man using echocardiography. Br Heart f 1973;35:1141-9.

24 Pearson AC, Labovitz AJ, Mrosek D, et al. Assessment of diastolic function in normal and hypertrophied hearts: comparison of Doppler echocardiography and M-mode echocardiography. Am Heart f 1987;113:1417-25.

25 Galderisi M, Benjamin EJ, Eraus JC, et al. Intra and interobserver reproducibility of Doppler assessed indexes of left ventricular diastolic function on a population based study (the Framingham heart study). Am f Cardiol 1992;70:1341-6.

26 Smucker ML, Tedesco CL, Manning SB, et al. Demonstration of an imbalance between coronary perfusion and excessive load as a mechanism of ischaemia during stress in patients with aortic stenosis. Circulation 1988;78:57382 .

27 Trenrouth RS, Phelps NC, Neill WA. Determinants of left ventricular hypertrophy and oxygen supply in chronic aortic valve disease. Circulation 1976;53:644-50.

28 Ingwall JS, Kramer MF, Fifer MA. The creatine kinase system in normal and diseased myocardium. $N \mathrm{Engl} \mathcal{F} \mathrm{Med}$ 1985;313:1050-4.

29 Ramirez ML, Wong M, Sadler N, et al. Doppler evaluation of bioprosthetic and mechanical aortic valves: data from four models in 107 ambulatory patients. Am Heart $\mathcal{F} 1988$; 115:418-25. 
30 Wazyrowski T, Kasprzak JD, Krzeminska-Pakula M, et al. Regression of left ventricular dilatation and hypertrophy . Int f Cardiol 1996:57:217-25.

31 Chaturvedi N, Athanassopoulos G, McKeigue PM, et al. Echocardiographic measures of left ventricular structure and their relation with rest and ambulatory blood pressure in blacks and whites in the United Kingdom. F $\mathrm{Am}$ Coll Cardiol 1994;24:1499-505.

32 Sartori MP, Quinones MA, Kuo LC. Relation of Doppler derived left ventricular filling parameters to age and radius/ thickness ratio in normal and pathological states. $A m^{f}$ Cardiol 1987;113:1417-25.
33 Harrison TR, Dixon K, Russel RO, et al. The relation of age to the duration of contraction, ejection and relaxation of the normal human heart. Am Heart f 1964;67:189-99.

34 Raff GL, Glantz SA. Volume loading slows left ventricular isovolumic relaxation rate. Circ Res 1981;48:813-24.

35 Starling MR, Montgomery DG, Mancini GB, et al. Load dependence of the rate of isovolumic relaxation in man. Circulation 1987;76:1274-81.

36 Diver DJ, Royal HD, Aroesty JM, et al. Diastolic function in patients with aortic stenosis: influence of left ventricular load reduction. 7 Am Coll Cardiol 1988;12:642-8.

\section{IMAGES IN CARDIOLOGY}

\section{Aortico-right ventricular tunnel with pulmonary stenosis in a neonate}

A 10 day old asymptomatic baby girl was evaluated for a to-and-fro systolic and diastolic murmur grade III/VI, audible along the left sternal border. The echocardiogram showed a valvar pulmonary stenosis with a maximum systolic gradient of $55 \mathrm{~mm} \mathrm{Hg}$ across a thick, poorly mobile pulmonary valve, and an aortico-right ventricular tunnel between the left aortic sinus and the right ventricle. The aortic orifice of the tunnel originated distal from the expected origin of the left coronary artery. Echocardiography (below left) and magnetic resonance imaging (MRI) (below right) revealed an abnormally large right coronary artery and only a tiny left anterior descending (LAD) coronary artery. The further course of the tunnel revealed an aneurysmatic dilatation and several stenoses. Because

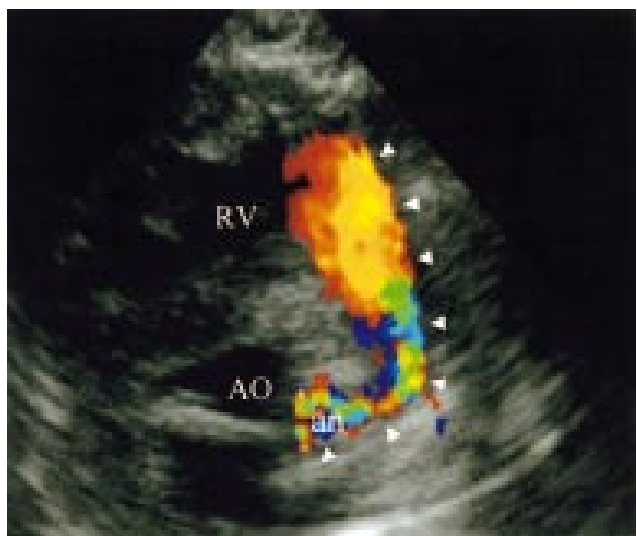

Parasternal short axis view echocardiogram at the level of the origin of the aortico-right ventricular tunnel from aorta ascendens (AO). The course of the tunnel is indicated with arrowheads down to the right ventricle $(R V)$. Doppler colour flow mapping shows turbulent flow across the tunnel and the aneurysm (an) distal from its origin from $A O$. of the association of the tunnel with pulmonary stenosis no heart failure developed, which made it possible to postpone the treatment beyond the neonatal period. At 5 months of age, the baby remained asymptomatic, but the maximum systolic gradient across the pulmonary stenosis increased to $75 \mathrm{~mm} \mathrm{Hg}$. The to-and-fro flow within the tunnel showed a systolic gradient of the right ventricle to the aorta of $5 \mathrm{~mm} \mathrm{Hg}$, and a diastolic gradient of the aorta to the right ventricle of $34 \mathrm{~mm} \mathrm{Hg}$. Because of an unsatisfactory relief of pulmonary stenosis with balloon valvuloplasty and failed coil closure of the tunnel, a surgical correction was performed. All findings were confirmed during surgery.

JAROSLAV HRUDA MARTHA A SOBOTKA-PLOJHAR ALBERT C VAN ROSSUM j.hruda@azvu.nl

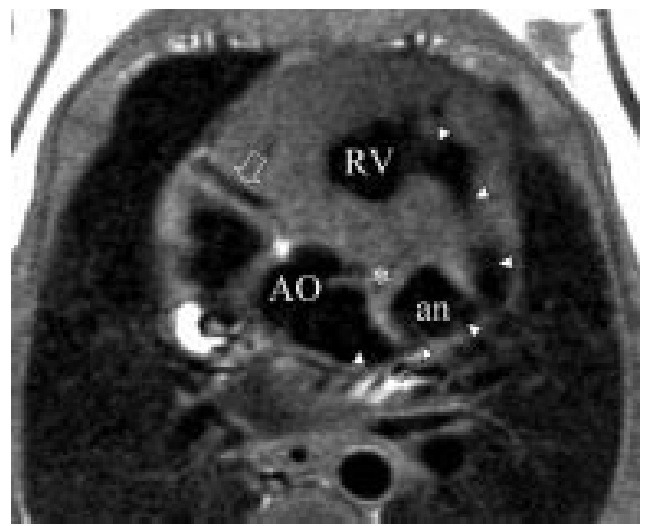

Transverse MRI study of the tunnel: aneurysmatic dilatation (an) within the tunnel (arrowheads) connecting aorta ascendens $(A O)$ and right ventricle $(R V)$. Dilated right coronary artery (arrows), hypoplastic $L A D$ (asterisk). 